\title{
Melatonin inhibits epithelial-to-mesenchymal transition in gastric cancer cells via attenuation of IL-1//NF-кB/MMP2/MMP9 signaling
}

\author{
XIAOTING WANG $^{1 *}$, BIN WANG $^{1 *}$, JIEQIONG XIE $^{1}$, DIYU HOU $^{1}$, HUI ZHANG $^{2}$ and HUIFANG HUANG ${ }^{1}$ \\ ${ }^{1}$ Central Laboratory, Fujian Medical University Union Hospital, Fuzhou, Fujian 350001; \\ ${ }^{2}$ Fujian Center for Safety Evaluation of New Drugs, Fujian Medical University, Fuzhou, Fujian 350108, P.R. China
}

Received March 2, 2018; Accepted July 7, 2018

DOI: $10.3892 /$ ijmm.2018.3788

\begin{abstract}
Although melatonin has been shown to exert marked antitumor effects against a variety of cancers, the underlying mechanisms remain to be fully elucidated. It has been hypothesized that the anticancer properties of melatonin are associated with its ability to suppress epithelial-to-mesenchymal transition (EMT) of cancer cells. In the present study, melatonin effectively suppressed interleukin (IL)-1 $\beta$-induced EMT in human gastric adenocarcinoma (GA) cells. Sequential treatment of GA cells with melatonin after IL-1 $\beta$ challenge markedly reversed the IL-1 $\beta$-induced morphological changes, reduced cell invasion and migration, increased $\beta$-catenin and E-cadherin expression, and downregulated fibronectin, vimentin, Snail, matrix metalloproteinase (MMP)2 and MMP9 expression. Moreover, IL-1 $\beta$-induced activation of NF- $\kappa \mathrm{B}$ was attenuated following treatment with melatonin. Knockdown of NF- $\kappa \mathrm{B}$ significantly reduced the IL-1 $\beta$-induced EMT in GA cells. Taken together, these findings indicate that melatonin may act by suppressing EMT and tumor progression by inhibiting $N F-\kappa B$ activity.
\end{abstract}

\section{Introduction}

Gastric cancer (GC) is the second most common malignant tumor worldwide, in terms of incidence as well as mortality (1). There is a long process before normal gastric mucosa becomes carcinomatous. During this process, normal gastric mucosa initially develops precancerous lesions, some of which may

Correspondence to: Professor Huifang Huang, Central Laboratory, Fujian Medical University Union Hospital, 29 Xinquan Road, Fuzhou, Fujian 350001, P.R. China

E-mail: huanghuif@126.com

*Contributed equally

Key words: melatonin, interleukin-1 $\beta$, gastric cancer, epithelial-to-mesenchymal transition, nuclear factor- $\kappa \mathrm{B}$, matrix metalloproteinase 2, matrix metalloproteinase 9 eventually become GC. Recent studies have demonstrated that epithelial-to-mesenchymal transition (EMT) is crucial role for the invasion and metastasis of all types of epithelial malignancies (2-4). EMT is a process whereby cells lose their epithelial traits of cell-cell adhesion and acquire mesenchymal traits, such as motility and invasiveness. In addition, it has been demonstrated that EMT is associated with inflammation. Importantly, inflammatory cytokines, particularly interleukin (IL)-1 $\beta$, can cause normal epithelial and cancer cells to undergo EMT $(5,6)$. However, the intrinsic mechanism has not been fully elucidated.

Melatonin is an important hormone that is synthesized and secreted by the pineal gland. Its biological roles include regulation of the circadian rhythm, as well as antioxidant, anti-aging and immunoregulatory actions. Various studies have reported that melatonin has significant antitumor activity against several types of cancers, such as breast, lung and colorectal cancer (7-9). Although the exact mechanism remains unknown, the anticancer effects of melatonin may be mediated by multiple pathways, including antagonism of growth factors, induction of tumor cell apoptosis, enhancement of immunity, adjustment of the psychological state, and synergy with other treatments (10-14).

Nuclear factor kappa B $(\mathrm{NF}-\kappa \mathrm{B})$ is a multifunctional transcription factor, which not only regulates numerous pathophysiological responses, but also plays an important role in tumor development, particularly in the progression of tumor invasion and metastasis (15-17). Numerous studies have indicated that continued activation of $\mathrm{NF}-\kappa \mathrm{B}$ is crucial for tissue malignant transformation $(18,19)$. However, the complex mechanism through which $\mathrm{NF}-\kappa \mathrm{B}$ regulates tumor metastasis is unclear.

It has been reported that $\mathrm{NF}-\kappa \mathrm{B}$ inhibits the expression of E-cadherin and desmoplakin and induces the expression of vimentin by promoting the expression of Snail (20), ZEB-1 and ZEB-2 (21), thereby initiating EMT. Other studies have demonstrated that melatonin exerts an inhibitory effect on $\mathrm{NF}-\kappa \mathrm{B}(22)$. However, to the best of our knowledge, there is currently no study investiagting these pathways in GC. The aim of the present study was to validate the effects of IL-1 $\beta$ and melatonin on the metastatic potential of gastric adenocarcinoma (GA) cell lines, and examine whether melatonin inhibits EMT 
by decreasing the nuclear translocation of NF- $\kappa$ B. Finally, the molecular mechanisms by which melatonin inhibits EMT in GA cells by targeting IL- $1 \beta / \mathrm{NF}-\kappa \mathrm{B} /$ matrix metalloproteinase (MMP)2/MMP9 signaling were investigated, hoping that this pathway may provide a novel therapeutic target for GC.

\section{Materials and methods}

Cell culture. The MGC80-3 and SGC-7901 cell lines were purchased from the Cell Bank of the Type Culture Collection of the Chinese Academy of Sciences (Shanghai, China). Cells were cultured in RPMI-1640 medium (HyClone, Logan, UT, USA) with $10 \%$ fetal bovine serum (HyClone) at $37^{\circ} \mathrm{C}$ in an incubator containing $5 \% \mathrm{CO}_{2}$.

Cell migration and invasion assays. For the invasion assay, MGC80-3 or SGC-7901 cells were placed in 24-well Transwell chambers (Costar, Cambridge, MA, USA) with $8-\mu \mathrm{m}$ pore filters coated with $60 \mu \mathrm{l}$ ice-cold Matrigel (BD Biosciences, San Jose, CA, USA), and diluted with serum-free RPMI-1640 medium. MGC80-3 or SGC-7901 cells (5x10 4 per well) in $200 \mu \mathrm{l}$ serum-free medium were seeded into the upper chamber, and $600 \mu \mathrm{l}$ medium containing $10 \%$ fetal bovine serum (as a chemoattractant) was added to the lower chamber. After $24 \mathrm{~h}$ of incubation, the cells were fixed with methanol and stained with crystal violet. Cotton swabs were used to remove non-invading cells from the upper surface of the membrane. Finally, cells were observed under a light microscope and photographed using a digital microscopic imaging system (Olympus, Tokyo, Japan). A total of 10 random fields were counted at a magnification of $\mathrm{x} 200$, and the results averaged for each condition. The migration assay was performed following the same procedure as described above, except that the wells were not coated with Matrigel and the incubation time was $20 \mathrm{~h}$.

Transfection with siRNA. siRNAs (GenePharma, Shanghai, China) were transfected into cells using Lipofectamine 2000 (Invitrogen; Thermo Fisher Scientific, Inc., Carlsbad, CA, USA) according to the manufacturer's instructions. Cells were exposed to $0,0.1,0.5$ or $1.5 \mathrm{mM}$ melatonin (Sigma-Aldrich; Merck KGaA, St. Louis, MO, USA) dissolved in ethanol. To evaluate the effects of IL-1 $\beta$ (Prospec, Rehovot, Israel), cells were treated with this agent for 30 min after transfection. NF- $\kappa$ Bp65 and control siRNA sequences are listed in Table I.

Western blot analysis. MGC80-3 or SGC-7901 cells were lysed on ice in radioimmunoprecipitation assay lysis buffer containing $1 \%$ phenylmethyl sulfonyl fluoride (Beyotime Institute of Biotechnology, Nantong, China). Western blot analysis was used to detect protein expression as described by Huang et al (23). The primary antibody used was rabbit polyclonal anti-human MMP2 (cat. no. 4022) or MMP9 (cat. no. 3852) (1:1,000; Cell Signaling Technology, Danvers, MA, USA); anti- $\beta$-actin (1:6,000; Cell Signaling Technology) was used as an internal control.

Gelatin zymography. The protease activities of MMP2 and MMP9 from the supernatants of MGC80-3 or SGC-7901 cells were measured by gelatin zymography. Briefly, $8 \%$ SDS-PAGE gel containing $1 \mathrm{mg} / \mathrm{ml}$ gelatin (Xinfan Technologies Inc., Shanghai, China) was used to separate the proteins with electrophoresis at a constant current of $40 \mathrm{~mA}$. Renaturing and developing the gels was conducted following the manufacturer's instructions. The gels were then stained with Coomassie blue and destained with a solution containing $7 \%$ acetic acid until clear bands of gelatin appeared on the dark background, indicating gelatin degradation. The gels were digitized using a scanner.

Reverse transcription-quantitative polymerase chain reaction $(R T-q P C R)$ analysis. Total RNA was extracted from MGC80-3 or SGC-7901 cells with TRIzol reagent (Invitrogen; Thermo Fisher Scientific, Inc.). An M-MLV RT kit (Invitrogen; Thermo Fisher Scientific, Inc.) was used for reverse transcription. The relative expression of $\beta$-catenin, fibronectin, E-cadherin, vimentin, Snail, NF- $\mathrm{B}, \mathrm{MMP} 2$ and MMP9 was detected using SYBR Green qPCR SuperMix (Roche, Basel, Switzerland) on a Two-step Real-Time PCR system (ABI7500, Thermo Fisher Scientific, Singapore). The primer sequences are given in Table II. Relative expression levels were normalized to glyceraldehyde 3 -phosphate dehydrogenase and calculated using the $2^{-\Delta \Delta C q}$ method.

Electrophoretic mobility shift assay (EMSA). EMSA was performed to determine the association between melatonin and NF- $\kappa \mathrm{B}$ activation in MGC80-3 and SGC-7901 cells. Nuclear extracts were prepared and an EMSA was performed according to the manufacturer's instructions (Viagene, Changzhou, China). Briefly, cell cultures were placed on ice $\left(1 \times 10^{7}\right.$ per $100-\mathrm{mm}$ dish), then rinsed three times with pre-cooled PBS prior to collection into a pre-cooled microtube. Subsequently, the cytoplasmic protein lysis buffer was added and the precipitate resuspended until no mass was identified. Then, the cell lysate was centrifuged at 14,000 x g for $10 \mathrm{~min}$ and the supernatant discarded. Solution buffer was added on the inner wall of the tube and centrifugation was performed several times at $12,000 \mathrm{x} \mathrm{g}$ for $5 \mathrm{~min}$. Subsequently, the extract buffer was added and the tubes were vortexed at the highest setting, then gently rocked on ice using a shaking platform. After centrifugation, the supernatant was transferred to new pre-cooled tubes. The nuclear protein extracts were incubated with a biotin-labeled $\mathrm{NF}-\kappa \mathrm{B}$ consensus oligonucleotide probe (5'-AGTTGAGGG GACTTTCCCAGGC-3') in binding buffer at room temperature for $20 \mathrm{~min}$. Following incubation, the samples were separated on a $5.5 \%$ polyacrylamide gel, transferred onto a nylon membrane and fixed on the membrane via ultraviolet crosslinking. The biotin-labeled probe was detected with streptavidin-HRP by ChemiDoc Touch Imaging System (Bio-Rad Laboratories, Inc., Hercules, CA, USA).

Statistical analysis. Statistical analyses were performed with SPSS version 17.0 software (SPSS Inc., Chicago, IL, USA). All data are expressed as means \pm standard deviation and were analyzed by the one-way analysis of variance, followed by Dunnett's T3 post-hoc test. $\mathrm{P}<0.05$ indicated a statistically significant difference. 
Table I. siRNAs targeting specific genes.

Sequence

\begin{tabular}{llc}
\cline { 2 - 3 } Gene & \multicolumn{1}{c}{ Sense (5'-3') } & Antisense (5'-3') \\
\hline NF-kBp65 siRNA & GGAGUACCCUGAGGCUAUATT & UAUAGCCUCAGGGUACUCCTT \\
Control siRNA & UUCUCCGAACGUGUCACGUTT & ACGUGACACGUUCGGAGAATT
\end{tabular}

Table II. Primers used for RT-qPCR.

\begin{tabular}{|c|c|c|c|}
\hline \multirow[b]{2}{*}{ Gene } & \multicolumn{2}{|c|}{ Sequence } & \multirow[b]{2}{*}{ Product size (bp) } \\
\hline & Sense $\left(5^{\prime}-3^{\prime}\right)$ & Antisense (5'-3') & \\
\hline$\beta$-catenin & TGCCAAGTGGGTGGTATAGAG & CGCTGGGTATCCTGATGTGC & 331 \\
\hline Fibronectin & CGAGCTTCCCCAACTGGTAACCC & GGTGGCACCTCTGGTGAGGC & 432 \\
\hline E-cadherin & TTGCTCACATTTCCСАACTCCTC & CACCTTCAGCCATCCTGTTTCTC & 234 \\
\hline Vimentin & GCTGAATGACCGCTTCGCCAACT & AGCTCCCGCATCTCCTCCTCGTA & 144 \\
\hline Snail & TCTAGGCCCTGGCTGCTACAA & ACATCTGAGTGGGTCTGGAGGTG & 131 \\
\hline $\mathrm{NF}-\kappa \mathrm{B}$ & CTGCATCCACAGTTTCCAGAACC & ACGCTGCTCTTCTATAGGAACTTGG & 295 \\
\hline MMP2 & CCTGATGTCCAGCGAGTG & AGCAGCCTAGCCAGTCG & 103 \\
\hline MMP9 & CAGTCCACCCTTGTGCTCTTC & TGCCACCCGAGTGTAACCAT & 124 \\
\hline GAPDH & AGAAGGCTGGGGCTCATTTG & AGGGGCCATCCACAGTCTTC & 238 \\
\hline
\end{tabular}

RT-qPCR, reverse transcription-quantitative polymerase chain reaction; NF- $\kappa \mathrm{B}$, nuclear factor $\kappa \mathrm{B}$; MMP, matrix metalloproteinase.

\section{Results}

Melatonin decreases $I L-1 \beta$-induced EMT in GA cells. The effect of melatonin on IL-1 $\beta$-induced EMT was investigated. MGC80-3 and SGC-7901 cells were treated with or without IL-1 $\beta(20 \mathrm{ng} / \mathrm{ml})$ for $30 \mathrm{~min}$ followed by incubation with $0.1,0.5$ or $1.5 \mathrm{mM}$ melatonin for $24 \mathrm{~h}$. Both GA cell types exhibited some morphological changes, including assuming a slender and spindle-like shape after treatment with IL-1 $\beta$ (Fig. 1A). These changes were inhibited by treatment with melatonin. Furthermore, IL-1 $\beta$ promoted cell invasion and migration, and this effect was decreased by melatonin, albeit not in a concentration-dependent manner (Fig. 1B and C).

To verify the effects of melatonin on EMT, the expression of EMT markers was assessed by the RT-qPCR assay. The results demonstrated that the mRNA expression of $\beta$-catenin and E-cadherin was reduced, while the mRNA expression of fibronectin, vimentin and Snail was increased, following addition of IL-1 $\beta(20 \mathrm{ng} / \mathrm{ml})$. Melatonin significantly inhibited the changes in the expression level of these genes (Fig. 1D). These findings indicated that melatonin inhibited IL-1 $\beta$-induced EMT in MGC80-3 and SGC-7901 cells.

Melatonin inhibits the expression and activity of MMP2 and $M M P 9$, which are upregulated in IL-1 $\beta$-induced EMT. The expression of MMP2 and MMP9 is closely associated with the invasion and metastasis of tumors (24). To investigate whether MMP2 and MMP9 were involved in IL-1 $\beta$-induced EMT in
GA cells, western blotting, RT-qPCR and gelatin zymography were applied to determine their expression and activity in GA cells. As expected, the expression and activity of MMP2 and MMP9 increased following stimulation with IL-1 $\beta$ (Fig. 2). Treatment with melatonin reduced these effects in MGC80-3 and SGC-7901 cells (Fig. 2).

Melatonin suppresses the $I L-1 \beta$-induced activation of $N F-\kappa B$ in $G A$ cells. Due to the key role of NF- $\mathrm{BB}$ in inflammation and tumor cell invasion $(25,26)$, it was hypothesized that the EMT observed in GA cells under IL-1 $\beta$ induction was attributable to increased NF- $\kappa \mathrm{B}$ activity. MGC80-3 and SGC-7901 cells were pretreated with or without IL-1 $\beta$ for $30 \mathrm{~min}$. Melatonin was then added for $24 \mathrm{~h}$, and $\mathrm{NF}-\kappa \mathrm{B}$ activity was observed by EMSA analysis. The results demonstrated that IL-1 $\beta$ induced $\mathrm{NF}-\kappa \mathrm{B}$ activation, whereas melatonin suppressed this effect (Fig. 3).

Inhibition of $N F-\kappa B$ activity reverses $I L-1 \beta$-induced $E M T$ in $G A$ cells. The potential role of $N F-\kappa B$ inhibition in preventing the development of IL- $1 \beta$-induced mesenchymal characteristics in GA cells was investigated. A siRNA specific for $\mathrm{NF}-\kappa \mathrm{B}$ was applied to these cells to block $\mathrm{NF}-\kappa \mathrm{B}$ activity. As shown in Fig. $4 \mathrm{~A}, \mathrm{NF}-\kappa \mathrm{B}$ siRNA markedly downregulated the expression of $N F-\kappa B$ at both the mRNA and protein levels. To verify that inhibiting $N F-\kappa B$ activity reversed the IL-1 $\beta$-induced EMT in GA cells, cell migration and invasion assays, western blotting and RT-qPCR analysis 

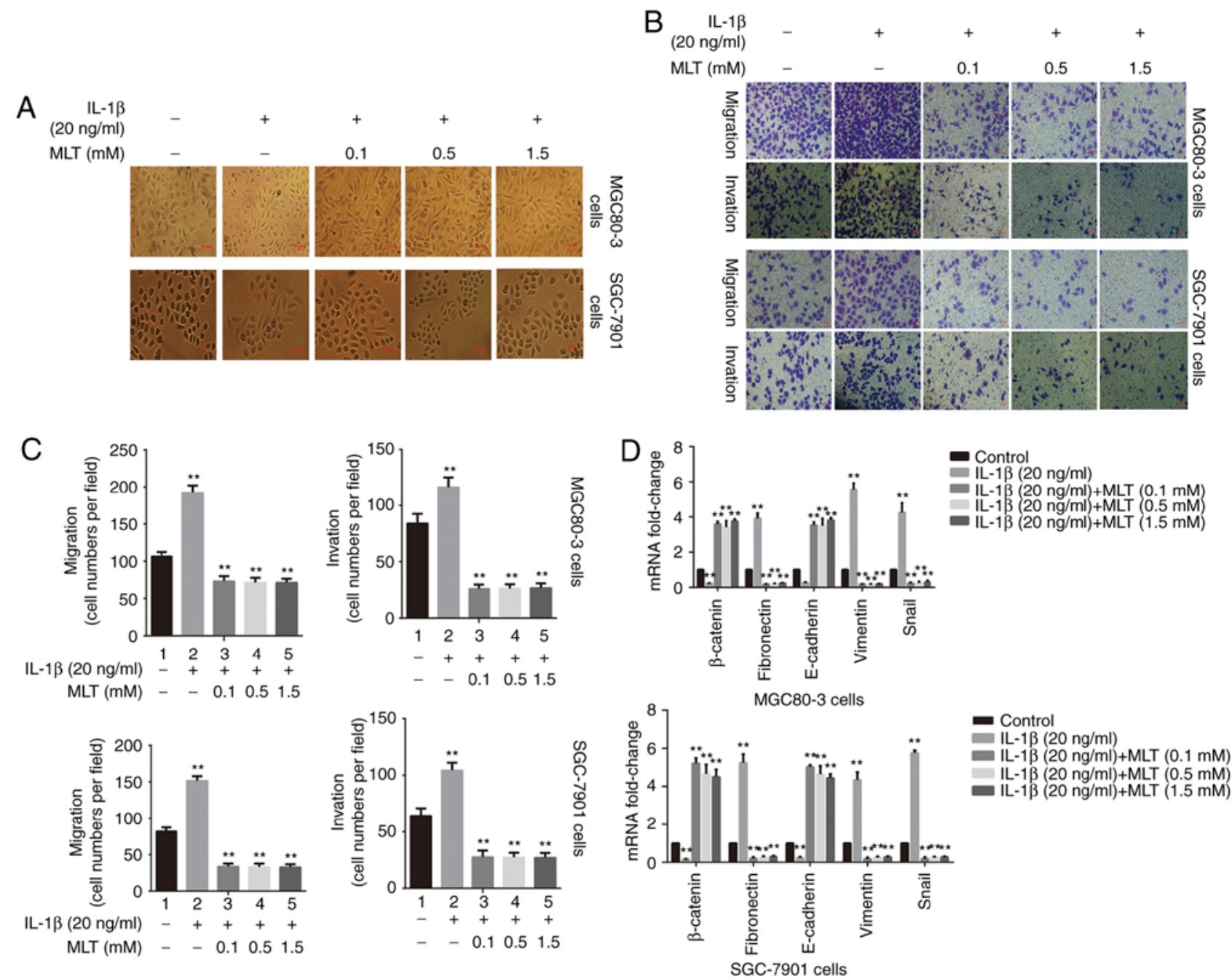
IL-1 1 (20 $\mathrm{ng} / \mathrm{ml})+\mathrm{MLT}(1.5 \mathrm{mM})$

Figure 1. Melatonin suppresses the IL-1 $\beta$-induced EMT in GA cells. (A) Morphological differences between IL-1 $\beta$-treated MGC80-3 and SGC-7901 cells, and IL-1 $\beta$-treated GA cells with melatonin. GA cells were pretreated with $20 \mathrm{ng} / \mathrm{ml} \mathrm{IL-1 \beta}$ for $30 \mathrm{~min}$ followed by incubation with melatonin $(0.1,0.5$ and $1.5 \mathrm{mM})$ for $24 \mathrm{~h}$. Representative images of cells treated with IL-1 $\beta$ demonstrated that the morphological changes of epithelial cells were reduced in the presence of melatonin (magnification, x200). (B and C) The effect of melatonin on IL-1 $\beta$-induced migration and invasion of GA cells was assessed using the Transwell assay. Treatment of GA cells with IL-1 $\beta$ increased cell migration and invasion, whereas these effects were inhibited by melatonin. ${ }^{*} \mathrm{P}<0.05$ and ${ }^{* *} \mathrm{P} \leq 0.01$ compared with the control group. Bars indicate the mean \pm standard deviation number of cells per field of view (magnification, $x 200$ ) in the migration and invasion assays. (D) Effect of IL-1 $\beta$ and melatonin on the expression of EMT markers. The expression of EMT markers, $\beta$-catenin, fibronectin, E-cadherin, vimentin and Snail were evaluated by RT-qPCR. Relative expression was obtained using the $2^{-\Delta \Delta C q}$ method after normalization to GAPDH. ${ }^{* *} \mathrm{P} \leq 0.01 \mathrm{compared}$ with the control group. IL-1 $\beta$, interleukin-1 $\beta$; MLT, melatonin; GA, gastric adenocarcinoma; EMT, epithelial-to-mesenchymal transition; RT-qPCR, reverse transcription-quantitative polymerase chain reaction.

were used. As expected, downregulation of NF- $\kappa \mathrm{B}$ not only significantly inhibited IL-1 $\beta$-induced cell migration and invasion, but also reduced the expression of mesenchymal markers (Fig. 4B and F).

\section{Discussion}

A growing body of evidence indicates that there is a close association between inflammation and tumor development. Tumors are stimulated and maintained by inflammatory signals from the tumor microenvironment, and this microenvironment plays a key role in cancer development $(27,28)$. EMT is a biological process whereby epithelial cells assume the characteristics of mesenchymal cells. During EMT, the ability of an epithelial cell to transform its morphological characteristics into those of a mesenchymal cell is a hallmark of tumor formation. Furthermore, numerous reports indicate that EMT is implicated in tumor cell invasion and metastasis (29). The inflammatory cytokine IL-1 $\beta$ is closely associated with EMT in breast cancer (30).

Our results indicated that MGC80-3 and SGC-7901 cells displayed mesenchymal morphological characteristics, along with increased cell migration and invasion, following treatment with IL-1 $\beta$. In addition, there were also changes in the expression of EMT-related genes. Specifically, after adding IL- $1 \beta$, the expression of $\beta$-catenin and E-cadherin was reduced, while the expression of fibronectin, vimentin and Snail was increased.

The expression of MMP2 and MMP9 is closely associated with the invasion and metastasis of cancer (24). The results of the present study are similar to those reported previously. The expression and activity of MMP2 and MMP9 increased following stimulation with IL-1 $\beta$. To the best of our knowledge, this study is among the first 


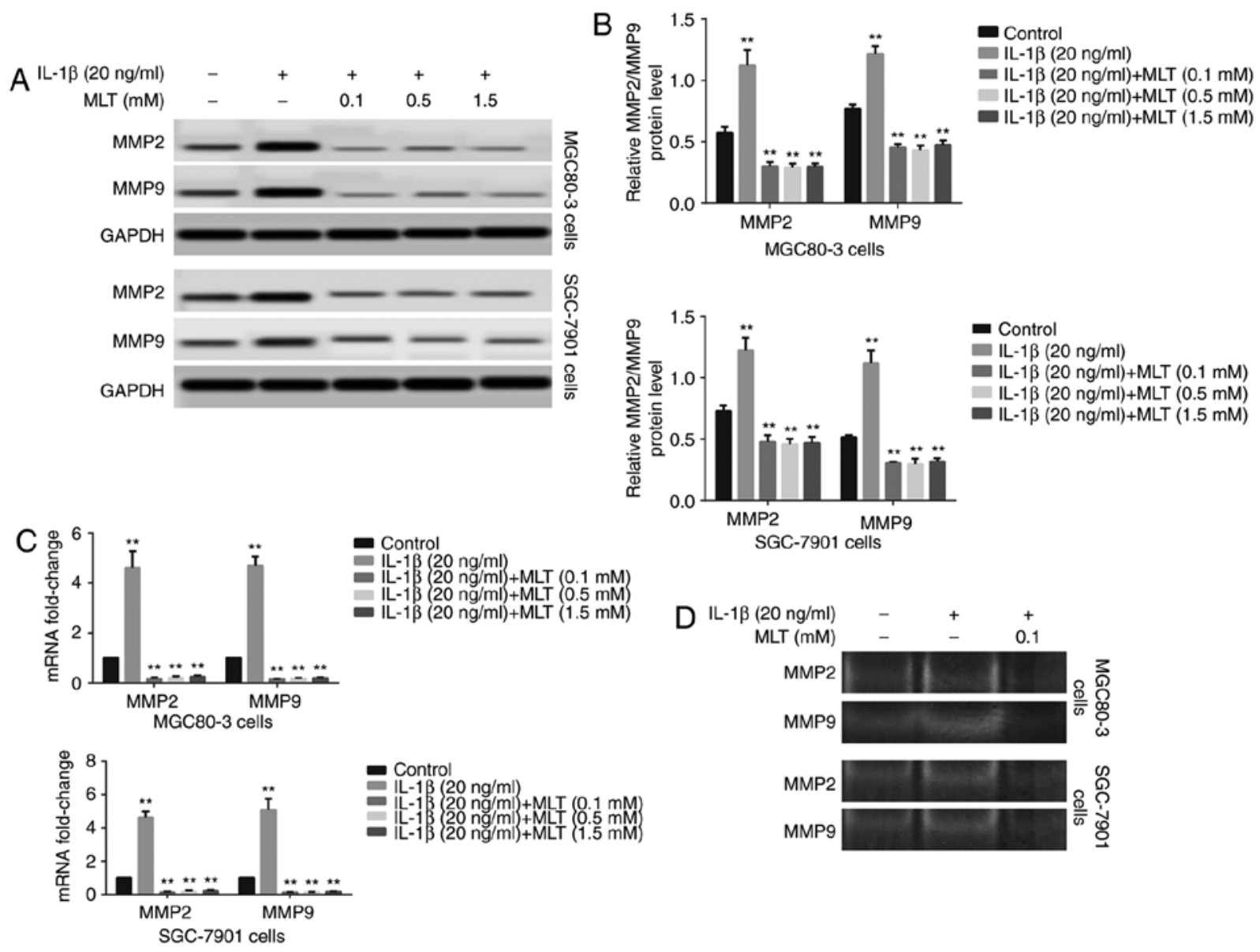

Figure 2. Melatonin inhibits the expression and the activity of MMP2 and MMP9, which are upregulated IL-1 $\beta$-induced EMT. (A and B) The expression of MMP2/MMP9 was examined by western blotting. GAPDH was used as an internal control. The relative density of MMP2/MMP9 was normalized to GAPDH, which was determined by densitometric analysis. Data represent the mean \pm standard deviation of three independent experiments. ${ }^{* * *} \mathrm{P} \leq 0.01$ compared with the control group. (C) RT-qPCR assay was performed to detect the mRNA level of MMP2/MMP9. The data were analyzed using the $2^{-\Delta \Delta C q}$ method. (D) Gelatin zymography assay revealed that MMP2 and MMP9 activity was increased in MGC80-3 and SGC-7901 cells in response to treatment with IL-1 $\beta$; this effect was blocked by MLT. ${ }^{* *} \mathrm{P} \leq 0.01$ compared with the control group. MLT, melatonin; MMP, matrix metalloproteinase; IL-1 $\beta$, interleukin-1 $\beta$; EMT, epithelial-to-mesenchymal transition; RT-qPCR, reverse transcription-quantitative polymerase chain reaction.

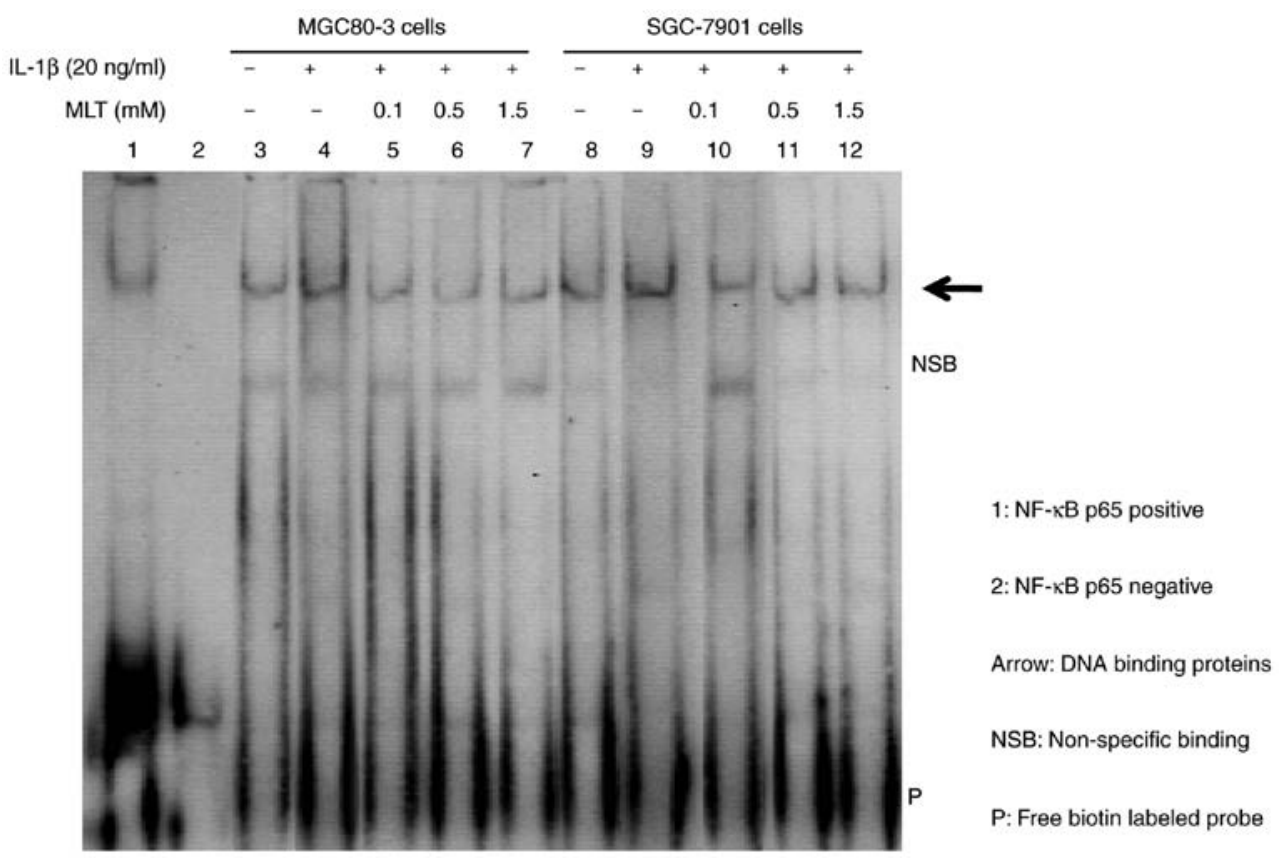

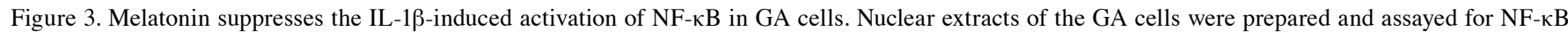
activation using EMSA. MLT, melatonin; GA, gastric adenocarcinoma; NF- $\kappa B$, nuclear factor $\kappa \mathrm{B}$; EMSA, electrophoretic mobility shift assay. 

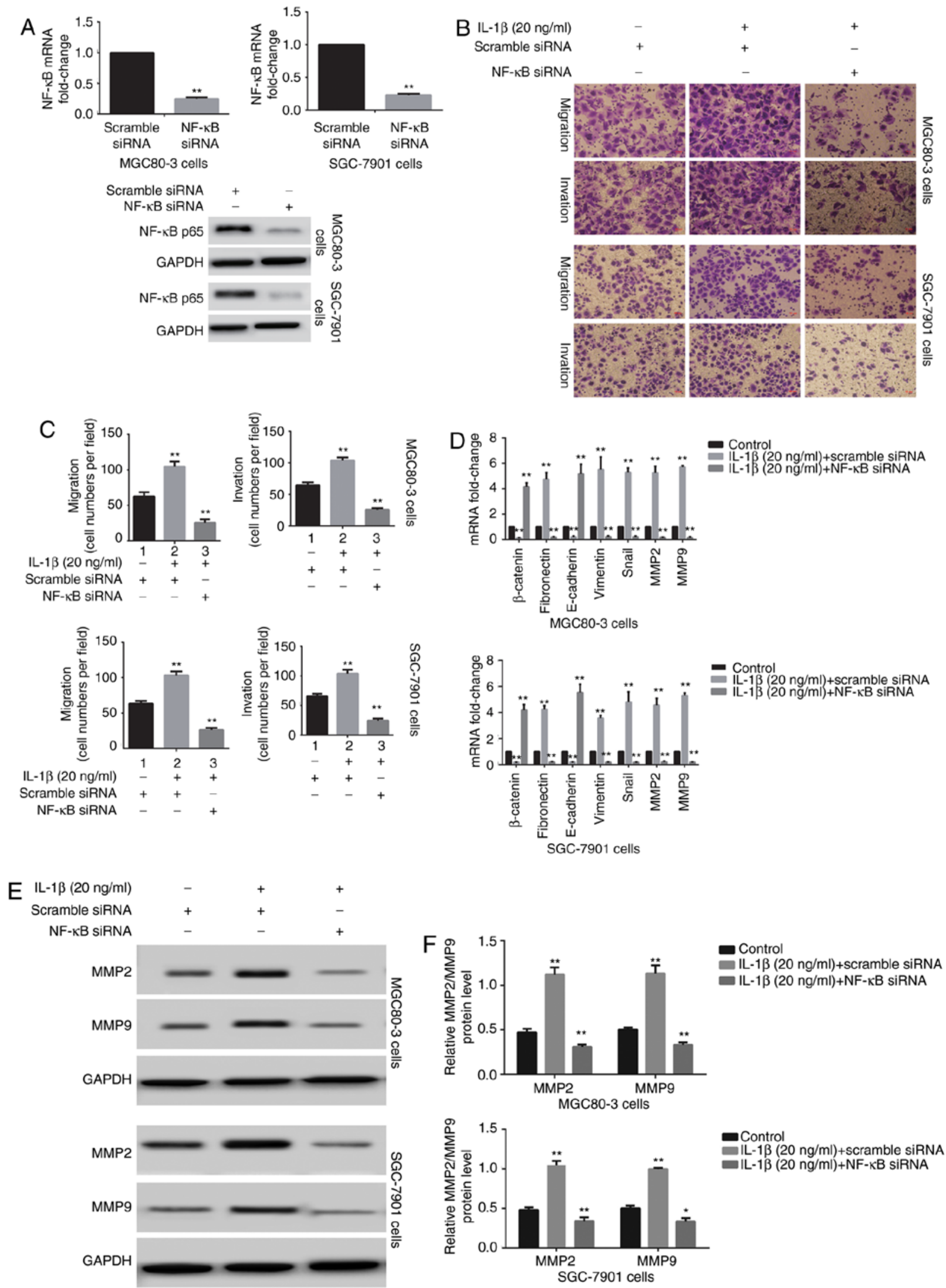

Figure 4. Inhibition of NF- $\mathrm{BB}$ activity reverses the IL-1 $\beta$-induced EMT in GA cells. (A) RT-qPCR and western blot analysis were conducted to detect the inhibitory efficacy of NF- $\kappa B$ siRNA in GA cells. (B and C) Transwell assay was performed to investigate the migration and invasion of NF- $\kappa B$ downregulated GA cells (magnification, $\mathrm{x} 200$ ). ${ }^{* *} \mathrm{P} \leq 0.01$ compared with the control group. (D) RT-qPCR analysis showed that mesenchymal marker mRNA was upregulated in both MGC80-3 and SGC-7901 cells in response to treatment with IL-1 $\beta$; this effect was blocked by NF- $\kappa B$ siRNA. ${ }^{* *} \mathrm{P} \leq 0.01$ compared with control group. (E and F) Effect of IL-1 $\beta$ and NF-kB siRNA on the expression of MMP2/MMP9. The expression of MMP2/MMP9 was evaluated by western blot analysis. All values are presented as mean \pm standard deviation of three independent experiments. ${ }^{*} \mathrm{P}<0.05,{ }^{* * *} \mathrm{P} \leq 0.01$ compared with the control group. NF- $\mathrm{kB}$, nuclear factor $\kappa \mathrm{B}$; IL-1 $\beta$, interleukin-1 $\beta$; EMT, epithelial-to-mesenchymal transition; GA, gastric adenocarcinoma; RT-qPCR, reverse transcription-quantitative polymerase chain reaction; MMP, matrix metalloproteinase. 
to demonstrate that IL-1 $\beta$ can promote EMT in GA cells; however, the potential underlying molecular mechanisms remain largely unknown.

Melatonin is a major hormone secreted mainly by the pineal gland. Its anticancer mechanisms include acceleration of tumor cell apoptosis, suppression of tumor cell proliferation, immunostimulation and synergistic activity with other treatments. Recent studies have demonstrated that melatonin notably decreases the risk of death and treatment resistance of multiple malignancies, particularly in breast cancer, colon cancer, melanoma, lung cancer and malignant glioblastoma $(7-9,31,32)$. A clinical study by Lissoni et al has demonstrated that the regression rate in patients with non-small-cell lung cancer or gastrointestinal cancer receiving combination therapy with chemotherapeutic drugs and melatonin was significantly higher compared with that in the group of patients receiving chemotherapy alone. Moreover, the 2-year survival rate was also higher in patients concomitantly treated with melatonin (10).

In the present study, the effect of melatonin on IL-1 $\beta$-induced EMT in MGC80-3 and SGC-7901 cells was investigated. Our findings suggested that melatonin inhibited the migration and invasion on GA cells, albeit not in a concentration-dependent manner. Furthermore, melatonin inhibited the IL-1 $\beta$-induced upregulation of MMP2 and MMP9 expression, and reversed the increased expression of EMT markers. Thus, it was concluded that melatonin decreased IL- $1 \beta$-induced EMT in GA cells, although fully elucidating the underlying mechanism requires further research.

Among several key factors related to EMT, NF- $\kappa \mathrm{B}$ is a vital element involved in the inflammatory process (33), as well as controlling the initiation and progression of several cancer types. NF- $\kappa \mathrm{B}$ induces the expression of Snail (20), ZEB-1 and ZEB2 (21) to promote EMT and cancer metastasis. It was also previously demonstrated that melatonin potently inhibits the activity of $\mathrm{NF}-\kappa \mathrm{B}$ (22). In the present study, EMSA analysis confirmed that IL-1 $\beta$ enhanced $\mathrm{NF}-\kappa \mathrm{B}$ transcriptional activity. Of note, treatment with melatonin significantly suppressed IL-1 $\beta$-induced NF- $\kappa \mathrm{B}$ transcriptional activity in MGC80-3 and SGC-7901 cells. Further research demonstrated that NF- $\kappa \mathrm{B}$ siRNA markedly reduced the expression of MMP2, MMP9, fibronectin, vimentin and Snail in IL-1 $\beta$-treated GA cells, indicating that the inhibition of $N F-\kappa B$ by a specific siRNA reversed the IL-1 $\beta$-induced EMT in GA cells. Furthermore, the cell migration and invasion assay in GA cells treated with IL-1 $\beta$ and $\mathrm{NF}-\kappa \mathrm{B}$ siRNA corroborated the decreased invasion and migration of these cells. Overall, our data indicated that melatonin inhibited IL-1 $\beta$-induced EMT by decreasing the nuclear translocation of NF- $\kappa \mathrm{B}$.

In summary, the results of the present suggested that melatonin suppresses IL-1 $\beta$-induced EMT by reducing the activity of $\mathrm{NF}-\kappa \mathrm{B}$ in GA cells. It was also determined that the molecular mechanisms by which melatonin inhibits EMT in GA cells involve targeting IL-1 $\beta / \mathrm{NF}-\kappa \mathrm{B} / \mathrm{MMP} 2 / \mathrm{MMP} 9$ signaling.

\section{Acknowledgements}

Not applicable.

\section{Funding}

This research was supported by the Fujian Provincial Natural Fund (2015J01472) for HH and Fujian Medical University Nursery Fund (2015MP019) for XW.

\section{Authors' contributions}

XW and $\mathrm{HH}$ designed the experiments. BW, JX, DH and $\mathrm{HZ}$ conducted the research. XW, BW and $\mathrm{HH}$ worked on the manuscript. All the authors have read and approved the final version of the manuscript.

\section{Availability of data and materials}

The analyzed data are available from the corresponding author upon reasonable request.

\section{Ethics approval and consent to participate}

Not applicable.

\section{Patient consent for publication}

Not applicable.

\section{Competing interests}

The authors declare that they have no conflict of interest.

\section{References}

1. Jemal A, Bray F, Center MM, Ferlay J, Ward E and Forman D: Global cancer statistics. CA Cancer J Clin 61: 69-90, 2011.

2. Yoshida T, Ozawa Y, Kimura T, Sato Y, Kuznetsov G, Xu S, Uesugi M, Agoulnik S, Taylor N, Funahashi Y and Matsui J: Eribulin mesilate suppresses experimental metastasis of breast cancer cells by reversing phenotype from epithelial-mesenchymal transition (EMT) to mesenchymal-epithelial transition (MET) states. Br J Cancer 110: 1497-1505, 2014.

3. Zheng X, Carstens JL, Kim J, Scheible M, Kaye J, Sugimoto H, Wu CC, LeBleu VS and Kalluri R: Epithelial-to-mesenchymal transition is dispensable for metastasis but induces chemoresistance in pancreatic cancer. Nature 527: 525-530, 2015.

4. Tungsukruthai S, Sritularak B and Chanvorachote P: Cycloartobiloxanthone inhibits migration and invasion of lung cancer cells. Anticancer Res 37: 6311-6319, 2017.

5. Jiménez-Garduño AM, Mendoza-Rodríguez MG, UrrutiaCabrera D, Domínguez-Robles MC, Perez-Yepez EA, Ayala-Sumuano JT and Meza I: IL-1 $\beta$ induced methylation of the estrogen receptor ERalpha gene correlates with EMT and chemoresistance in breast cancer cells. Biochem Biophys Res Commun 490: 780-785, 2017.

6. Wang J, Bao L, Yu B, Liu Z, Han W, Deng C and Guo C: Interleukin-1 $\beta$ promotes epithelial-derived alveolar elastogenesis via $\alpha v \beta 6$ integrin-dependent TGF- $\beta$ activation. Cell Physiol Biochem 36: 2198-216, 2015.

7. Kim W, Jeong JW and Kim JE: CCAR 2 deficiency augments genotoxic stress-induced apoptosis in the presence of melatonin in non-small cell lung cancer cells. Tumour Biol 35: 10919-10929, 2014.

8. Mao L, Yuan L, Xiang S, Zeringue SB, Dauchy RT, Blask DE, Hauch A and Hill SM: Molecular deficiency (ies) in MT Mela- $_{1}$ tonin signaling pathway underlies the melatonin-unresponsive phenotype in MDA-MB-231 human breast cancer cells. J Pineal Res 56: 246-253, 2014.

9. Pariente R, Bejarano I, Rodriguez AB, Pariente JA and Espino J: Melatonin increases the effect of 5-fluorouracil-based chemotherapy in human colorectal adenocarcinoma cells in vitro. Mol Cell Biochem 440: 43-51, 2018. 
10. Lissoni P: Biochemotherapy with standard chemotherapies plus the pineal hormone melatonin in the treatment of advanced solid neoplasms. Pathol Biol (Paris) 55: 201-204, 2007.

11. Martín-Renedo J, Mauriz JL, Jorquera F, Ruiz-Andrés O, González P and González-Gallego J: Melatonin induces cell cycle arrest and apoptosis in hepatocarcinoma HepG2 cell line. J Pineal Res 45: 532-540, 2008.

12. Korkmaz A, Tamura H, Manchester LC, Ogden GB, Tan DX and Reiter RJ: Combination of melatonin and a peroxisome proliferator-activated receptor-gamma agonist induces apoptosis in a breast cancer cell line. J Pineal Res 46: 115-116, 2009.

13. Pizarro JG, Yeste-Velasco M, Esparza JL, Verdaguer E, Pallàs M, Camins A and Folch J: The antiproliferative activity of melatonin in B65 rat dopaminergic neuroblastoma cells is related to the downregulation of cell cycle-related genes. J Pineal Res 45: 8-16, 2008.

14. Zupancic D, Jezernik K and Vidmar G: Effect of melatonin on apoptosis, proliferation and differentiation of urothelial cells after cyclophosphamide treatment. J Pineal Res 44: 299-306, 2008.

15. Peng Z, Geh E, Chen L, Meng Q, Fan Y, Sartor M, Shertzer HG, Liu ZG, Puga A and Xia Y: Inhibitor of kappaB kinase beta regulates redox homeostasis by controlling the constitutive levels of glutathione. Mol Pharmacol 77: 784-792, 2010.

16. Kang H, Jang SW, Pak JH and Shim S: Glaucine inhibits breast cancer cell migration and invasion by inhibiting MMP-9 gene expression through the suppression of NF-kappaB activation. Mol Cell Biochemist 403: 85-94, 2015.

17. Yang SS, Li XM, Yang M, Ren XL, Hu JL, Zhu XH, Wang FF, Zeng ZC, Li JY, Cheng ZQ, et al: FMNL2 destabilises COMMD10 to activate NF- $\kappa$ B pathway in invasion and metastasis of colorectal cancer. Br J Cancer 117: 1164-1175, 2017.

18. Krenn PW, Hofbauer SW, Pucher S, Hutterer E, Hinterseer E, Denk U, Asslaber D, Ganghammer S, Sternberg C, Neureiter D, et al: ILK induction in lymphoid organs by a $\mathrm{TNF} \alpha-\mathrm{NF}-\kappa \mathrm{B}-$ regulated pathway promotes the development of chronic lymphocytic leukemia. Cancer Res 76: 2186-2196, 2016.

19. Barham W, Chen L, Tikhomirov O, Onishko H, Gleaves L, Stricker TP, Blackwell TS and Yull FE: Aberrant activation of $\mathrm{NF}-\mathrm{\kappa B}$ signaling in mammary epithelium leads to abnormal growth and ductal carcinoma in situ. BMC Cancer 15: 647, 2015.

20. Lu Z, Li Y, Wang J, Che Y, Sun S, Huang J, Chen Z and He J: Long non-coding RNA NKILA inhibits migration and invasion of non-small cell lung cancer via NF-кB/Snail pathway. J Exp Clin Cancer Res 36: 54, 2017.

21. Chua HL, Bhat-Nakshatri P, Clare SE, Morimiya A, Badve S and Nakshatri H: NF-kappaB represses E-cadherin expression and enhances epithelial to mesenchymal transition of mammary epithelial cells: Potential involvement of ZEB-1 and ZEB-2. Oncogene 26: 711-724, 2007.
22. Li W, Wu J, Li Z, Zhou Z, Zheng C, Lin L, Tan B, Huang M and Fan M: Melatonin induces cell apoptosis in Mia PaCa-2 cells via the suppression of nuclear factor- $\kappa \mathrm{B}$ and activation of ERK and JNK: A novel therapeutic implication for pancreatic cancer. Oncol Rep 36: 2861-2867, 2016.

23. Huang Q, Lan F, Zheng Z, Xie F, Han J, Dong L, Xie Y and Zheng F: Akt2 kinase suppresses glyceraldehyde-3-phosphate dehydrogenase (GAPDH)-mediated apoptosis in ovarian cancer cells via phosphorylating GAPDH at threonine 237 and decreasing its nuclear translocation. J Biol Chem 286: 42211-42220, 2011.

24. Van Tubergen EA, Banerjee R, Liu M, Vander Broek R, Light E, Kuo S, Feinberg SE, Willis AL, Wolf G, Carey T, et al: Inactivation or loss of TTP promotes invasion in head and neck cancer via transcript stabilization and secretion of MMP9, MMP2, and IL-6. Clin Cancer Res 19: 1169-1179, 2013.

25. Aggarwal BB. Nuclear factor-kappaB: The enemy within. Cancer Cell 6: 203-208, 2004

26. Aggarwal BB, Vijayalekshmi RV and Sung B: Targeting inflammatory pathways for prevention and therapy of cancer: Short-term friend, long-term foe. Clin Cancer Res 15: 425-430, 2009.

27. Qin LX: Inflammatory immune responses in tumor microenvironment and metastasis of hepatocellular carcinoma. Cancer Microenviron 5: 203-209, 2012.

28. Leonardi GC, Candido S, Cervello M, Nicolosi D, Raiti F, Travali S, Spandidos DA and Libra M: The tumor microenvironment in hepatocellular carcinoma (Review). Int J Oncol 40: $1733-1747,2012$

29. Tsai JH and Yang J: Epithelial-mesenchymal plasticity in carcinoma metastasis. Genes Dev 27: 2192-2206, 2013.

30. Soria G, Ofri-Shahak M, Haas I, Yaal-Hahoshen N, Leider-Trejo L, Leibovich-Rivkin T, Weitzenfeld P, Meshel T, Shabtai E, Gutman M and Ben-Baruch A: Inflammatory mediators in breast cancer: Coordinated expression of TNF $\alpha$ \& IL-1 $\beta$ with CCL2 \& CCL5 and effects on epithelial-to-mesenchymal transition. BMC Cancer 11: 130, 2011.

31. Martin V, Sanchez-Sanchez AM, Puente-Moncada N, Gomez-Lobo M, Alvarez-Vega MA, Antolín I and Rodriguez C: Involvement of autophagy in melatonin-induced cytotoxicity in glioma-initiating cells. J Pineal Res 57: 308-316, 2014

32. Kim TK, Lin Z, Tidwell WJ, Li W and Slominski AT: Melatonin and its metabolites accumulate in the human epidermis in vivo and inhibit proliferation and tyrosinase activity in epidermal melanocytes in vitro. Mol Cell Endocrinol 404: 1-8, 2015.

33. Pal S, Bhattacharjee A, Ali A, Mandal NC, Mandal SC and Pal M: Chronic inflammation and cancer: Potential chemoprevention through nuclear factor kappa B and p53 mutual antagonism. J Inflamm (Lond) 11: 23, 2014. 